\title{
The Nutrition of a Lactobacillus acidophilus Variant Isolated from the Duodenum of a chick
}

\author{
By J. E. FORD AND M. ROGOSA* \\ National Institute for Research in Dairying, Shinfield, Reading, England
}

(Received 25 November 1960)

\begin{abstract}
SUMMARY
Allen, Stephens, Jaffe \& Wakelam (1959) isolated a lactobacillus which they found to require a growth factor present in malt distillers' dried solubles. We have identified the organism as belonging to the subgroup Thermobacterium Orla-Jensen. It was grown through many serial passages in a chemically defined medium containing thymidine, and had no residual indispensable requirement for unidentified nutrients.
\end{abstract}

\section{INTRODUCTION}

Malt distillers' dried solubles (MDDS), made from the liquor remaining in the whisky still after the spirit has been distilled, have been reported to contain unidentified factors which promote growth in chicks (Wakelam \& Jaffe, 1959). The feeding of MDDS to chicks changed the composition of the bacterial flora of the duodenum and caused an increase in the numbers of an unidentified species of lactobacillus (Allen, Stephens, Jaffe \& Wakelam, 1959). Allen et al. isolated this organism and found that it required a growth factor present in MDDS. Further tests with a variety of feed supplements showed that stimulation of chick growth was correlated with growth-promoting activity for the Lactobacillus sp. It seemed probable that the factor which stimulated growth in the chicks was the same as that required by the Lactobacillus sp. Through the kindness of Drs K. A. Allen and J. Stephens we have been able to make a further study of the nutrition of this organism.

\section{METHODS}

Organism. Cultures of the organism can be obtained from the National Collection of Dairy Organisms (NCDO) at the National Institute for Research in Dairying, Shinfield, Reading, as culture no. NCDO 1417. It will be referred to in this paper as strain 1417. We have found that it belongs to the subgroup Thermobacterium OrlaJensen and has the cultural characteristics of Lactobacillus acidophilus (see Rogosa \& Sharpe, 1959) except that it does not ferment trehalose.

Maintenance of organism. The organism was maintained by monthly transfer in the basal medium (Table 1 ) supplemented with $10 \%(\mathrm{v} / \mathrm{v})$ of an aqueous extract of MDDS. (To $50 \mathrm{~g}$ MDDS were added $400 \mathrm{ml}$. water and enough $\mathrm{N}-\mathrm{H}_{3} \mathrm{PO}_{4}$ to bring to $\mathrm{pH} \mathrm{6.5}$. The mixture was heated in flowing steam for $30 \mathrm{~min}$., cooled and centrifuged. The supernatant fluid was diluted to $500 \mathrm{ml}$. with water.)

* Present address: National Institute of Dental Research, National Institutes of Health, U.S. Department of Health, Education and Welfare, Public Health Service, Bethesda 14, Maryland, U.S.A. 
Cultures were first grown for $18 \mathrm{hr}$. at $37^{\circ}$ in the liquid medium and were then transferred as stabs to the same medium solidified with $1.5 \%(\mathrm{w} / \mathrm{v})$ agar. After incubation for $24 \mathrm{hr}$. these stab cultures were stored at $2^{\circ}$.

Preparation of inocula for tests. The cultures used to inoculate the tests were grown for $18 \mathrm{hr}$. at $37^{\circ}$ in the basal medium supplemented with $10 \%(\mathrm{v} / \mathrm{v})$ of the MDDS extract. They were diluted $1 / 10$ with sterile $0.9 \%(\mathrm{w} / \mathrm{v}) \mathrm{NaCl}$ solution and one drop added to each assay tube.

Basal medium. The composition of the basal medium is shown in Table 1. For some tests the medium was modified by using the following mixture of amino acids to replace the hydrolysed casein and Tryptone: L-leucine, L-isoleucine, L-valine, L-lysine, L-arginine, L-methionine, $500 \mathrm{mg}$. each; L-glutamic acid, L-asparagine, 1 g. each; L-alanine, glycine, L-serine, L-aspartic acid, L-tyrosine, L-proline, Lhistidine, L-phenylalanine, L-threonine, L-tryptophan, $200 \mathrm{mg}$. each; in $200 \mathrm{ml}$. of $5 \times$ single strength medium.

\section{Table 1. Basal medium. Composition to give $5 \times$ the concentration of final medium}

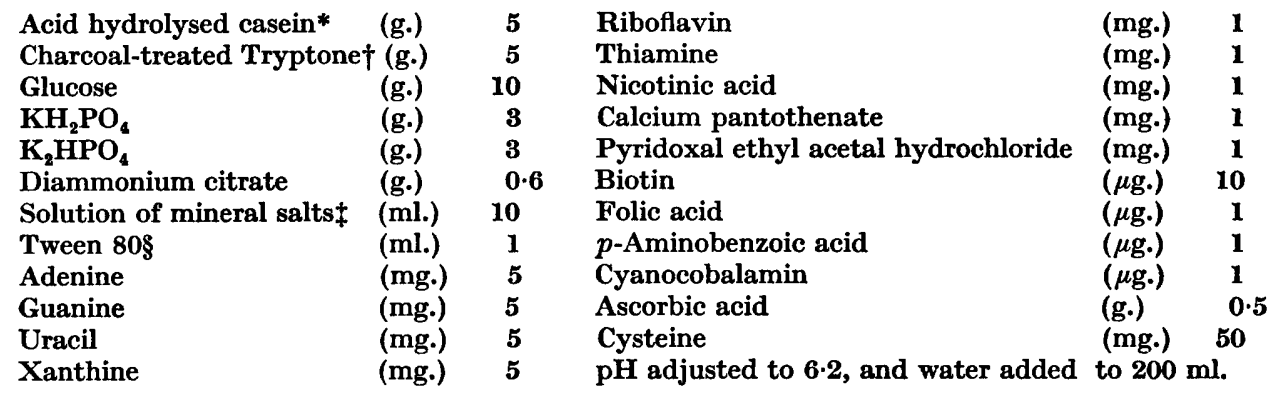

* Allen and Hanburys, Ltd. 'Vitamin free' grade.

$\uparrow$ Prepared as follows: $50 \mathrm{~g}$. Tryptone (Oxo Ltd.) were dissolved in $400 \mathrm{ml}$. water, and the solution adjusted to pH 4.0 with acetic acid. Charcoal (10 g. Sutcliffe and Speakman Ltd.; Grade 5) was added, and the whole stirred for $10 \mathrm{~min}$. and then filtered. The filtrate was adjusted to $\mathrm{pH}$ 6.0 with $10 \mathrm{~N}-\mathrm{KOH}$ solution, and a further $5 \mathrm{~g}$. charcoal added. After stirring for $5 \mathrm{~min}$. the mixture was filtered, and to the filtrate were added: DL-tryptophan (1 g.), L-tyrosine (200 mg.), Lphenylalanine (200 mg.), L-proline (100 mg.) and L-histidine (100 mg.). Finally, water was added to $500 \mathrm{ml}$.

$\ddagger$ Contains $\mathrm{MgCl}_{2} .6 \mathrm{H}_{2} \mathrm{O}, 20 \mathrm{~g}$.; $\mathrm{CaCl}_{2}, 5 \mathrm{~g}$.; $\mathrm{FeCl}_{3} .6 \mathrm{H}_{2} \mathrm{O}, 0.5 \mathrm{~g}$; $\mathrm{ZnSO}_{4} .7 \mathrm{H}_{2} \mathrm{O}, 0.5 \mathrm{~g}$.; $\mathrm{MnSO}_{4}$. $4 \mathrm{H}_{2} \mathrm{O}, 0.25 \mathrm{~g}$; $\mathrm{CoCl}_{2} .6 \mathrm{H}_{2} \mathrm{O}, 0 \cdot 25 \mathrm{~g}$; $\mathrm{CuSO}_{4} .5 \mathrm{H}_{2} \mathrm{O}, 0.25 \mathrm{~g}$; $\mathrm{VSO}_{4}, 0.25 \mathrm{~g} . ; \mathrm{Na}_{2} \mathrm{MoO}_{4}, 0.25 \mathrm{~g}$; dissolved in $1 \mathrm{l}$. distilled water with addition of $\mathrm{N}-\mathrm{H}_{2} \mathrm{SO}_{4}$ to clear.

8 Polyoxyethylene sorbitan mono-oleate.

Test procedure. The growth promoting activities of the test preparations were judged by comparison with the activity of a 1/5 dilution of the MDDS extract. This 'standard' and the 'test' solutions were added to series of tubes in amounts of 1, 2, 4 and $8 \mathrm{ml}$., together with $2 \mathrm{ml}$. portions of $5 \times$ single strength basal medium and water to make final volumes of $10 \mathrm{ml}$. The tubes were then capped and autoclaved at $115^{\circ}$ for $10 \mathrm{~min}$. After cooling to room temperature the tubes were inoculated and incubated at $37^{\circ}$ for $24 \mathrm{hr}$. Growth responses were measured turbidimetrically with a Lumetron model $400 \mathrm{~A}$ photometer (Photovolt Corporation, 95 Madison Avenue, New York, 16 N.Y., U.S.A.). 


\section{RESULTS}

Several proprietary extracts of yeast proved about as active as MDDS in promoting the growth of strain 1417. Yeast nucleic acid (British Drug Houses Ltd., Poole, Dorset, England) and herring sperm deoxyribonucleic acid (L. Light and Co., Ltd., Poyle Trading Estate, Colnbrook, Buckinghamshire, England) showed relatively little activity (about $2 \%$ that of MDDS) but depolymerization of these compounds with cobra venom caused a considerable increase in their activity to equal, or slightly exceeding, that of MDDS. Ribose and deoxyribose were inactive. Adenosine, adenylic acid, guanosine, guanylic acid, cytidine and uridine were

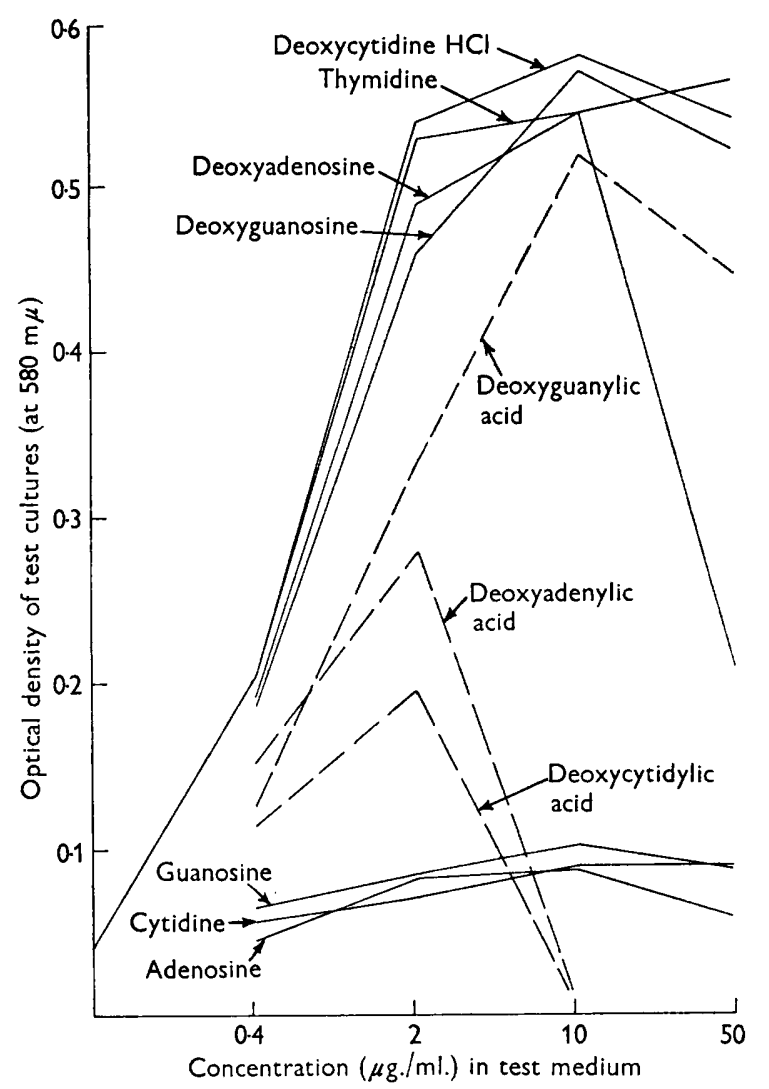

Fig. 1. Growth responses of strain 1417 to graded concentration of various nucleosides and nucleotides.

inactive or only very slightly active at 10 or $50 \mu \mathrm{g} . / \mathrm{ml}$. But deoxyadenosine, deoxyguanosine, deoxycytidine and thymidine were highly active, giving at $2 \mu \mathrm{g} . / \mathrm{ml}$. a growth response greater than that elicited by about $4 \mathrm{mg}$. MDDS/ml. Deoxyadenylic acid, deoxyguanylic acid and deoxycytidylic acid, at 0.4 and $2.0 \mu \mathrm{g} . / \mathrm{ml}$., were somewhat less active than the corresponding deoxynucleosides. At 10 and $50 \mu \mathrm{g} . / \mathrm{ml}$. deoxyadenylic acid and deoxycytidylic acid were inhibitory. The very slight activity of some of the ribosides tested might have been due to contamination 
of these compounds with deoxyribosides. Figure 1 shows the growth responses of strain 1417 to graded concentrations of several of these compounds.

MDDS contains a high proportion of yeast and of the extracellular products of yeast metabolism. It undergoes a mild alkaline hydrolysis with lime at about pH 10.5 during the process of manufacture and would doubtless contain deoxynucleosides, whose presence might account for most of its growth-promoting activity for strain 1417 .

The organism was grown through many serial passages in chemically defined medium supplemented with thymidine, and appeared to have no residual indispensable requirement for unidentified nutrients. The cultures grew faster, however, and to about $20 \%$ greater population, in basal medium supplemented with $10 \%(\mathrm{v} / \mathrm{v})$ of the MDDS extract than in the same basal medium supplemented with any one or all four of the deoxynucleosides. It is evident that the extract of MDDS contributes stimulatory nutrients other than the necessary deoxyribosides. It provides additional buffering which alone might have permitted greater total bacterial growth.

Requirements for exogenous deoxyribosides have been noted for several of the lactic acid bacteria, among them 'Thermobacterium acidophilus $R 26$ ', which was recommended by Hoff-Jørgensen (1951) for the microbiological assay of deoxyribonucleic acid and deoxyribonucleosides, and is presumably of the same species as that studied by us. In both organisms the requirement for deoxyribosides persists in the presence of vitamin $\mathbf{B}_{12}$. Lactobacillus delbrueckii also shows an absolute requirement for deoxynucleosides; but in certain other species the requirement is non-specific and is not apparent in the presence of vitamin $B_{12}$ or enzymic digests of casein, or under reducing conditions induced by cysteine or ascorbic acid, or by growth in an atmosphere of hydrogen (Kitay, McNutt \& Snell, 1949; Kitay, MeNutt \& Snell, 1950).

\section{REFERENCES}

Allen, K. A., Stephens, J., Jaffe, W. P. \& Wakelam, J. A. (1959). Unidentified growth factors. Nature, Lond. 184, 271.

HofF-Jørgensen, E. (1951). A microbiological assay of deoxyribonucleosides and deoxyribonucleic acid. Biochem. J. 50, 400.

Kitay, E., MCNuTt, W. S. \& SNell, E. E. (1949). The nonspecificity of thymidine as a growth factor for lactic acid bacteria. J. biol. Chem. 177, 993.

Kitay, E., McNutt, W. S. \& Snell, E. E. (1950). Deoxyribosides and vitamin $B_{12}$ as growth factors for lactic acid bacteria. J. Bact. 59, 727.

Rogosa, M. \& Sharpe, M. E. (1959). An approach to the classification of the lactobacilli. J. appl. Bact. 22, 329.

Wakelam, J. A. \& JAFFe, W. P. (1959). Unidentified chick growth factors. Nature, Lond. 184, 272. 